\title{
Bone Fragility Fractures in CKD Patients
}

\author{
Ana Pimentel ${ }^{1} \cdot$ Pablo Ureña-Torres $^{1,2} \cdot$ Jordi Bover $^{3} \cdot$ Jose Luis Fernandez-Martín ${ }^{4} \cdot$ Martine Cohen-Solal $^{5}$
}

Received: 8 October 2020 / Accepted: 4 November 2020 / Published online: 21 November 2020

(c) The Author(s) 2020

\begin{abstract}
Chronic kidney diseases (CKD) are associated with mineral and bone diseases (MBD), including pain, bone loss, and fractures. Bone fragility related to CKD includes the risk factors observed in osteoporosis in addition to those related to CKD, resulting in a higher risk of mortality related to fractures. Unawareness of such complications led to a poor management of fractures and a lack of preventive approaches. The current guidelines of the Kidney Disease Improving Global Outcomes (KDIGO) recommend the assessment of bone mineral density if results will impact treatment decision. In addition to bone density, circulating biomarkers of mineral, serum bone turnover markers, and imaging techniques are currently available to evaluate the fracture risk. The purpose of this review is to provide an overview of the epidemiology and pathogenesis of CKD-associated bone loss. The contribution of the current tools and other techniques in development are discussed. We here propose a current view of how to better predict bone fragility and the therapeutic options in CKD.
\end{abstract}

Keywords Bone $\cdot$ Fracture $\cdot$ Bone mineral density $\cdot$ CKD-MBD $\cdot$ Phosphate $\cdot$ Calcium $\cdot$ Parathyroid hormone $\cdot$ Imaging

\section{Introduction}

The high morbidity and mortality rates observed in progressive chronic kidney disease (CKD) are tightly associated to the underlying metabolic bone alterations. The mineral and bone disorders (MBD) associated with CKD include bone, biochemical, and cardiovascular abnormalities in the same entity since they share common pathophysiological mechanisms. This current new definition of CKD-MBD aims at a better awareness of concommitant bone and cardiovascular events and shows that common molecules are

Martine Cohen-Solal

martine.cohen-solal@inserm.fr

1 AURA Paris-Nord, Saint-Ouen, France

2 Necker Hospital, University of Paris Descartes, Department of Renal Physiology, Paris, France

3 Fundació Puigvert, Universitat Autònoma, IIB Sant Pau, REDinREN, Nephrology Department, Barcelona, Catalonia, Spain

$4 \quad$ Instituto de Investigación Sanitaria del Principado de Asturias (ISPA), REDinREN del ISCIII, Hospital Universitario Central de Asturias. Universidad de Oviedo, Bone and Mineral Research Unit, Oviedo, Asturias, Spain

5 INSERM U1132 \& Université de Paris, Hôpital Lariboisière, Department of Rheumatology, Paris, France involved in both tissues breakdown. The initial characterization of previously called renal osteodystrophy (ROD) was based on bone biopsy and is extended nowadays to bone markers of fragility, including biochemistry and imaging. Bone fragility includes all the aspects that lead to fractures, particularly bone volume, structure, rate of remodeling, as well as mineralization defects which can be also observed in CKD. Fractures are the end results of skeletal fragility, the prevention of which being a major objective. The evaluation of fracture risk is required in light of high mortality risk and hospitalization costs related to fracture in dialysis patients [1-5], which enhances the economic burden of CKD-MBD.

An important contribution of the Kidney Disease Improving Global Outcomes (KDIGO) 2017 revised version [6] compared to 2009 KDIGO CKD-MBD guidelines [7] is to recommend the assessment of bone mineral density (BMD) in case a treatment is considered, thus highlighting the need of a better assessment of CKD patients suffering from skeletal fractures. However, there is no recommendation about which BMD should be assessed and at which frequency in CKD patients as it is in osteoporotic postmenopausal women. Indeed, in this population, a second BMD performed 3 years after the initial measurement was not associated with improved discrimination between women who did and did not experience subsequent hip fracture or major 
osteoporotic fracture beyond the baseline BMD value alone and should not routinely be performed [8]

\section{Epidemiology of Skeletal Fractures in CKD}

The life expectancy of CKD patients is constantly improving because of a better prevention and management of complications. The prevalence of skeletal fractures in the general population as well as in subjects with CKD has significantly increased in the recent years along with aging and the related increase in bone loss. This can be evidenced by several longitudinal studies reporting the incidence of fractures during the last decade [3, 9-27]. They found the fracture incidence to raise progressively from 15.0 to $20.5,24.2,31.2$, and $46.3 / 1000$ person-years for CKD stages 1 to $2,3 \mathrm{a}, 3 \mathrm{~b}$, and 4 , respectively [28]. The risk of skeletal fracture is up to 5 times higher in individuals with an estimated glomerular filtration rate $(\mathrm{eGFR})<15$ versus $>60 \mathrm{ml} / \mathrm{min} / 1.73 \mathrm{~m}^{2}$. This is particularly true in CKD patients older than 65 years who show the highest rate of fractures, with $1 / 10$ women and $1 / 20$ men experiencing at least one fracture in the subsequent 3 years of follow-up [29]. In a recent Dialysis Outcomes and Practice Patterns Study (DOPPS) report, the incidence of skeletal fractures was significantly higher for patients receiving hemodialysis therapy than in the general population with a 3.7-fold increase of the unadjusted relative risk of death [4].

Peripheral fractures are the best documented. The incidence of hip fractures is four-fold higher for dialysis patients than for the general population after adjustment for age, gender, and ethnicity $[9,30]$. Moreover, the incidence of hip fracture in CKD patients differs by ethnicity and sex, being 3 times higher for Caucasian than African-American [1] and twice higher for women than men [3, 21, 27, 31]. They are also associated with several risk factors including older age, low body mass index, and long dialysis vintage, as well as with a history of prior hip fracture [23]. A recent study evaluated the association between CKD stages G3-G5 versus eGFR $>60 \mathrm{ml} / \mathrm{min} / 1.73 \mathrm{~m}^{2}$ and the risk of a new nonhip fracture or fragility fracture in patients with a first hip fracture. It found that the risk of a subsequent major non-hip fragility fractures following hip fracture was not increased in patients with CKD G3-G5 compared to eGFR > $60 \mathrm{ml} /$ $\min / 1.73 \mathrm{~m}^{2}$. Mortality risk was higher in both hip fracture and non-hip fracture patients with CKD G4 and G5 [32].

The most recent and the largest epidemiologic study assessing the incidence and the risk factors associated with hip fractures is a South Korean report from 352,624 CKD adult subjects [33]. They found that lower eGFR and high urine albumin levels were associated with a higher risk of hip fracture. The HR for hip fracture was 1.89 among participants with eGFRs of $30-44$ and $15-29 \mathrm{~mL} / \mathrm{min} / 1.73 \mathrm{~m}^{2}$ relative to those with an eGFR $\geq 60 \mathrm{~mL} / \mathrm{min} / 1.73 \mathrm{~m}^{2}$, respectively. The HRs were 1.30 for moderate albuminuria and 1.58 for severe albuminuria. Participants with albuminuria had a higher risk of hip fracture than those without albuminuria, even when they belonged to the same eGFR category. The effects of each $10 \mathrm{~mL} / \mathrm{min} / 1.73 \mathrm{~m}^{2}$ decrease in eGFR were stronger with advancing albuminuria severity.

The US Medicare data for hemodialysis patients have recently reported a downward hip fracture incidence trends from 2000 to late 2009 [1], most prominent in older adults of both genders [34]. Indeed, the incidence of hip fracture increased when dialysis treatment was initiated from 1996 to 2004 and then declined until 2009, although it remained higher than in 1996 [16]. The relative risk of hip fractures starts to increase as early as age 55 years and is more increased for CKD patients with high bone turnover disease rather than with low bone turnover disease [23, 27]. The risk of skeletal fractures combines classical risk factors that are applied for osteoporosis in addition to those associated with CKD. After 4 years of dialysis, the age-standardized incidence ratio of hip fracture was $9.83(8.61,11.2 ; 95 \%$ C.I.) for men and 8.10 (7.23, 9.07; 95\% C.I.) for women [9]. Even in renal transplant recipients, prior dialysis vintage is associated with increased risk of hip fracture [2, 35]. Because of a rare collection of vertebral fractures, the prevalence of this major bone fragility is poorly documented in cohort and dialysis registers. This has been reported to be low, ranging from 7 to $20 \%$ [36, 37], and only $1 \%$ of patients appear to have vertebral fractures based on clinical diagnosis in a single clinical trial [38]. It is likely that this is underestimated because of the lack of systematic radiographic imaging or in the presence of spinal pain or the difficulty to differentiate a mild vertebral fracture from deformities as seen in Scheuermann disease. A more recent analysis of a prospective cohort of 612 patients with 3-5 stage CKD revealed $18 \%$ of vertebral fractures. After a 3-year follow-up, the prevalence of fractures was correlated with a poor survival and an independent predictor of all-cause mortality [39].

The risk of mortality following a hip fracture is significantly high in CKD patients, $[40,41]$ but has essentially remained unchanged since 1998 for either sex [31]. The thirty-day mortality rate after hip fracture is of $16 \%$ for CKD patients initiating dialysis and age $>67$ years in the United States [16]. The hip fracture-related mortality risk is also two times higher with eGFR $<45$ than $\geq 45 \mathrm{ml} / \mathrm{min} / 1.73 \mathrm{~m}^{2}$ [42]. In the French national database in 2010, a significant higher mortality rate was observed after hip fracture in patients on dialysis therapy compared to those without dialysis, up to $12 \%$ for men and $8 \%$ for women, as well as a longer hospital stay in the intensive care unit [3]. Several major risk factors were found to be associated with those hip fractures, particularly the presence of cardiovascular diseases and dementia. 


\section{Evaluation of Fracture Risk in CKD-MBD}

Bone strength is based on both the quantity and quality of bone, influenced by several factors such as the level of bone remodeling or the matrix composition. Bone quantity can be estimated by bone density while bone quality by the microarchitecture, both leading to a reduced mechanical bone adaptation. Thus, most fractures occurring after a fall or a low kinetics trauma take place in a bone with low mechanical strength. Cumulative studies revealed that the high fracture risk results from the combination of CKD-induced changes in bone and mineral metabolism in addition to the classical fracture risk factors observed in the non-CKD population including age, gender, diabetes, and glucocorticoid use. Several imaging and biochemical markers, here below described, have demonstrated their usefulness to assess the fracture risk in CKD population.

\section{Bone Mineral Density}

In non-CKD patients, the reduction of BMD as measured by dual-energy $\mathrm{x}$-ray absorptiometry (DEXA) predicts the fracture risk. Osteoporosis is defined by a T-score below 2.5 standard deviations (number of standard deviations of BMD below the mean BMD for the young healthy population). The relevance is limited in patients with scoliosis, osteoarthritis at the lumbar spine, and noteworthy in the presence of vascular calcifications that are frequent in CKD and which overestimate the BMD. Another limitation of BMD and T-score is that it does cannot distinguish the type of ROD and cannot discriminate osteoporosis as a low bone mass than low bone density related to mineralization defect. A meta-analysis showed that BMD is lower in pre-dialysis and dialysis CKD patients with fractures compared to those without [43]. Despite these findings, BMD measurement was not recommended in the 2009 KDIGO guidelines because of inconsistency in the results obtained from most of cross-sectional studies and the mild reduction of BMD that cannot be used at the individual level. More recently, prospective cohort studies showed good predictive value of BMD for risk of peripheral fracture and hip fractures in CKD stages 3-5D [12, 28, 44, 45]. This prompted the recent 2017 KDIGO guidelines to recommend BMD measurement if results will impact treatment decisions, as advocated by the World Health Organization (WHO) for the general population.

Nevertheless, scarce data are available for the prediction of vertebral fractures, one of the main hallmarks of bone fragility. Case-control studies with a small number of dialysis patients revealed that a low BMD at the lumbar spine was associated with vertebral fractures and with the prevalent or self-reported peripheral fractures [46]. In a meta-analysis of 13 studies [43], only one mentioned a relationship between vertebral fracture and the dialysis vintage, but did not find any association between BMD and the risk of fracture [11]. Albeit a lower discriminative value of BMD in CKD, recommendations of BMD measurement for predicting peripheral fractures draw the attention to a better assessment of a well-recognized marker of fragility fractures. In addition, the Fracture Risk Assessment Tool (FRAX) index is sufficient for 10-year prediction of major osteoporotic fractures, assessing clinical risk factors together with BMD [44, 47], in particular in older patients with CKD stages 2-5 [47]. A recent study in 718 Polish hemodialysis patients, who were followed up for two years, showed that the Polish version of FRAX $>5 \%$ (without the DXA examination) and some particular variables of the FRAX calculator had a sensitivity of $70.0 \%$ and a specificity of $69.8 \%$ as the prognostic threshold for major bone fractures. Again, in this study, FRAX sensitivity for bone fracture prediction was significantly higher, but specificity is lower than those of FRAX $\geq 10 \%$, used in general Polish population. The reason for this can be an underestimation of bone fracture risk with FRAX in dialysis patients [48].

Bone diseases related to CKD represent a large spectrum of histological features, all associated with a high risk of fracture. Indeed, low BMD may be observed in osteoporosis, but also in hyperparathyroidism, osteomalacia, and adynamic bone diseases. This difficulty of characterizing the bone disease requires additional evaluation in order to address specific treatment of the cause.

\section{Macro and Microarchitecture of Bone}

Altered hip geometry, as derived from DEXA hip measurement, has been associated with the risk of fracture. Non-CKD women with hip fractures have thinner femoral cortices and longer femoral-neck axis length than women without fractures. Such DXA-derived cortical parameters were reported in patients in CKD patients [49]. Although hip structural values are correlated with BMD, whether they provide additional information independent of BMD and if this improves fracture prediction remains unknown [50]. Further investigations using the new three-dimensional (3D)-DXA software will be useful in CKD as previously shown in patients with primary hyperparathyroidism [51].

Another marker emerged recently to evaluate bone strength. The Trabecular Bone Score (TBS) is a gray-level textural index derived by an algorithm that analyzes the spatial organization of pixel intensity from lumbar spine DEXA images. TBS is not a direct measurement of bone microarchitecture, but it is correlated to it. TBS can be used to predict fractures independent of major clinical 
risk factors or a real BMD measured in the general population [52]. In a cohort of 1426 participants older than 40 years and followed for a mean of 4.7 years, including 199 patients with eGFR $<60 \mathrm{ml} / \mathrm{mn} / 1.73 \mathrm{~m}^{2}(72.4 \%$ CKD stage $3 a, 25.1 \%$ CKD stage $3 b$, and $2.5 \%$ CKD stage 4 ), low lumbar spine TBS was independently associated with increased fracture risk when kidney function was low, providing a new tool to better identify the patients at risk [53].

As discussed above, BMD measurement by DEXA is insufficient to assess the fracture risk partly because of a weak discriminating power between cortical and trabecular bone. Indeed, bone strength depends on cortical bone which is highly altered in CKD. Bone biopsies obtained from CKD patients revealed that low bone turnover is associated with normal cortical porosity, while high serum PTH levels are present with normal cortical thickness and high trabecular bone volume [54]. However, the biopsies performed were not systematic, but for research purposes, introducing a recruitment bias for a clear-cut interpretation. Nevertheless, assessment of cortical bone structure in CKD is crucial since predominantly affected by bone loss and highly associated with peripheral fractures at any skeletal sites [55]. Undoubtedly, such structural components are additional parameters to be included in the treatment decision in addition to the rate of bone remodeling and bone and mineral biomarkers.

Quantitative computed tomography (QCT) revealed a higher number of patients experiencing bone loss at the hip as compared with BMD measured by DEXA [56]. The peripheral QCT device from Stratec, which measures only BMD at the mid-radius and then mainly cortical bone, showed that high PTH, long dialysis vintage, and cortical BMD were significant predictors of skeletal changes [57]. BMD and microarchitecture assessed by high-resolution peripheral quantitative tomography (HRpQCT) allow a separate measurement of cortical and trabecular bone [58] and help to determine the underlying mechanisms of bone loss [59]. In CKD stages 2-4, HRpQCT showed early impairment of trabecular bone, before the onset of secondary hyperparathyroidism (SHPT). This could explain in part the high risk of fractures in early CKD [60] but also in patients with long CKD history [58]. HRpQCT measurements allow to distinguish between cortical and trabecular bone density in vivo. It assesses both bone volume and density in the same compartment, thus potentially yielding information regarding bone mineralization as well. A recent study in 68 dialysis children with bone biopsy determination showed that $76 \%$ of patients had normal/high bone turnover, $13 \%$ had adynamic bone disease, and $11 \%$ had osteomalacia. Bone formation rate did not correlate with any HRpQCT determinations. Bone volume measurements were highly correlated between bone histomorphometry and HRpQCT (bone volume/tissue volume between the two techniques) [61]. We have also recently analyzed bone trans-iliac biopsies performed for vertebral or hip fracture in 12 adult dialysis patients and compared with bone microarchitecture assessed by twodimension histology (2D) and in vitro microcomputed tomography $(3 \mathrm{D}-\mu \mathrm{CT})$ as well as with microarchitecture data obtained from HRpQCT. We found that $3 \mathrm{D}-\mu \mathrm{CT}$ was a reliable method for the measurement of cortical bone in bone biopsies. However, only HRpQCT allows discriminating patients with multiple fractures [62].

Bone loss observed in CKD stage 5D affected cortical BMD and thickness which is correlated with high PTH and dialysis vintage, but not with trabecular bone [55]. However, levels of neither calciotropic hormones such as PTH nor bone remodeling markers were associated with changes in trabecular density, number, and heterogeneity. These data have been challenged more recently by a study using bone biopsy data that correlated cortical BMD to biochemical markers [63]. Cortical BMD was negatively correlated to serum PTH, TRAP5b (tartrate-resistant acid phosphatase $5 b$ ), and BSAP (bone-specific alkaline phosphatase) levels, suggesting that low remodeling rate is associated with higher bone density and strength. These controversial data are likely related to changes that occur at different remodeling rates, biomarkers reflecting the level of bone remodeling at short term while cortical thickness integrating remodeling rates for a long period. Research should address new imaging of the appendicular skeleton to estimate cortical bone loss [58]. For example, analysis of bone matrix, including collagen and mineral properties, should be developed [64, 65]. Despite the great interest of predicting the risk of fracture and identifying people who will benefit from therapeutic interventions, most of these new tools are not widely available, as well as evidence of additional interest compared to DEXA [66].

\section{Bone Biomarkers}

Since several decades, PTH remains the best surrogate biomarker to evaluate the level of bone remodeling in CKD. Most CKD patients with adynamic bone disease displayed serum PTH level $<150 \mathrm{pg} / \mathrm{mL}$ [67] and those with histological SHPT show PTH values $>600 \mathrm{pg} / \mathrm{ml}$ [68]. Although within the KDIGO recommended PTH target of 2-9 the normal range, those values within the target range do not discriminate the different forms of ROD [69] and both high and low circulating PTH levels can be associated with high fracture rate and mortality risk $[4,5$, 20, 23, 36, 70-72]. Interestingly, serum PTH levels, just before the occurrence of a new fracture, are associated with the increased risk of fracture, in contrast to baseline or time-averaged serum PTH levels. The upper and lower PTH values of the U-shaped PTH curve are associated with a significantly increased risk of fracture as compared with PTH values within the recommended NKF/K-DOQI 
target values [12]. Therefore, treatment should not be based on a single PTH value but rather on a trend of PTH within the previous months. As mentioned in the KDIGO 2017 guidelines, "persistently" and "progressively rising" PTH level should be considered, rather than "above the upper normal limit". Total or subtotal parathyroidectomy reduces serum PTH levels and subsequently bone turnover, improves BMD and reduces long-term risk for fractures in CKD stage 5D patients [73-75]. Other circulating bone biomarkers provide additional information of the rate of bone turnover and microstructure of bone. These include cross-linked collagen type I peptide (CTX) and tartrateresistant acid phosphatase 5B (TRAP5b for bone resorption, as well as bone-specific alkaline phosphatase, and procollagen type $1 \mathrm{~N}$-terminal pro-peptide (P1NP) for bone formation [56]. A recent study has shown the predictive value of association of these markers and PTH to predict bone fragility [76]. In another recent study, not yet investigated for fracture prediction, a panel of 4 microRNAs was superior to circulating concentrations of bonespecific alkaline phosphatase and CTX for discriminating low bone turnover within individual cancellous, endocortical, and intracortical bone compartments [77].

The phosphate/FGF23/alpha-Klotho axis is another determinant of bone mineralization in CKD. Circulating phosphate levels slowly increase with the progression of CKD and both directly and indirectly contribute to the skeletal fragility associated with CKD-MBD, in part via the stimulation of PTH and FGF23 production [78]. The role of serum phosphate as a bone fracture risk factor has been poorly studied. In general population, the results from the Dutch Rotterdam Study (RS-I, RS-II and RS-III) and the US Osteoporotic Fractures in Men (MrOS) study including 12,216 patients followed up to 10.9 years showed that serum phosphate was significantly associated with bone fractures [79]. Quintiles $4(3.3-3.5 \mathrm{mg} / \mathrm{dL})$ and $5(>3.5 \mathrm{mg} / \mathrm{dL})$ of serum phosphate were associated with a higher risk of incident of all types of fractures compared with quintile 1 . In this study, serum phosphate was associated with fracture risk in subjects without CKD and also in men with CKD. In men with CKD the association between serum phosphate and fracture risk was even stronger than in non-CKD subjects. In 2004, Block el al. found that serum phosphate was significantly associated with bone fracture-related hospitalization with a relative risk of 1.12 per $\mathrm{mg} / \mathrm{dL}$ increase in serum phosphate in hemodialysis patients [80]. Unpublished data from the COSMOS study (Current management Of Secondary hyperparathyroidism: a Multicentre Observational Study) are in the same line, showing, in a period of 3-year follow-up, that high serum phosphate is associated with a higher incidence of bone fractures. By contrast, Aleksova et al [81] found that low serum phosphate was associated with a higher risk of bone fractures in transplanted patients.
Serum FGF23 levels significantly increase in early CKD stages and coincide with the decrease of $1,25 \mathrm{OH} 2 \mathrm{D}$ [82]. FGF23 is mainly produced by osteocytes and osteoblasts and exerts its major physiological actions in the kidney, stimulating urinary phosphate excretion and inhibiting calcitriol synthesis after binding to a complex formed by alpha-klotho and canonical FGF receptors. FGF23 plays an important role in regulating bone mineralization. In CKD stage 5D patients, BMD is not correlated with serum FGF23 levels [83]. However, high FGF23 and low klotho levels were found in CKD patients with type 2 diabetes compared to controls and even further in CKD with fractures [84]. High FGF23 was associated with reduced osteoid thickness in children both with normal renal function and dialysis [85], through the regulation of tissue non-specific alkaline phosphatase activity (TNAP) via FGFR-3, vitamin D, and klotho-independent manner. Finally, excessive FGF23 contributes to bone loss in CKD via an alpha-klotho-dependent mechanism and the stimulation of the osteoblast Wnt inhibitor Dkk1 [86]. Therefore, inactivation of the Wnt/b-catenin signaling pathway by the altered phosphate/FGF23/Klotho axis may provide another autocrine/paracrine mechanism favoring bone loss in CKD-MBD.

\section{Contribution of Bone Histology}

Bone histomorphometry is the gold standard to evaluate bone abnormalities of CKD-MBD [87], although not routinely recommended because of its invasive nature and the limited number of specialized laboratories. Histological signs of high bone turnover are expected in that $85-90 \%$ of patients have increased serum PTH level in CKD stages 3-5 [88, 89]. Accordingly, histological high bone turnover in $47.2 \%$ of patients with CKD stages $3-4$ and in $61.4 \%$ with CKD stage 5 [90]. However, low-turnover bone disease has also been reported as being the predominant pattern in 2 small populations with pre-dialysis and a wide eGFR range ( $<5$ to $\left.90 \mathrm{ml} / \mathrm{min} / 1.73 \mathrm{~m}^{2}\right)$ [91, 92] and in most CKD patients on dialysis $[54,93]$. These conflicting results might be related to the recruitment of patients; bone biopsies being mostly performed in symptomatic patients with no systematic analysis for epidemiologic purposes are influenced by several confounding factors. Moreover, the lack of clear-cut and quantitative definition of adynamic bone disease (ABD) and the absence of previous labeling do not allow drawing clear conclusions.

In addition, CKD progression might result in changes from low bone turnover at earlier stages to high bone turnover features at later stages [94] and there is no association between fracture incidence and the histological type of bone diseases. Finally, bone biopsy may show mineralization defects and osteomalacia, even in the absence of marked changes in circulating biomarkers. Actually, the first causes 
of bone mineralization defect are vitamin $\mathrm{D}$ deficient-related osteomalacia, hypophosphatemia, and aluminum overload. Osteomalacia remains present in long-term dialysis therapy and remains a cause of fractures. Moreover, the use of the new bone nomenclature (TMV), which now adds bone mineralization indices to turnover and volume should contribute to a better definition of the classical renal osteodystrophy and a better estimation of fracture risk and understanding clinical features.

\section{Therapeutical Management of Fractures in CKD}

Several medications have been shown to reduce the fracture rate in patients with low BMD. All of them can be proposed for the prevention of fractures when eGFR is above $30 \mathrm{ml} /$ $\min / 1.73 \mathrm{~m}^{2}$ after correction of 25OHD insufficiency. In any case, supplementation of vitamin D is strongly recommended when initiate therapies regardless of kidney function. Specific cause of non-osteoporotic fractures should be discarded and required specific treatments. The presence of osteomalacia can be suggested by low serum 25OHD levels, long-lasting hypocalcemia or hypophosphate, and high alkaline phosphatase levels [95]. All the medications that received the approval for the prevention of fractures will follow the same recommendations as in non-CKD patients. This is the case of raloxifene, bisphosphonates, and denosumab, the three of them being pure inhibitors of bone resorption while teriparatide, the human recombinant $\mathrm{PTH}$, increased bone resorption and formation with a positive bone balance in favor of bone formation. Treatment of CKD stage 4-5D patients with osteoporosis requires more caution and should be discussed after the correction of mineral biomarkers. There is no evidence that any treatment prevents the fracture rate in patients with low BMD alone. Nevertheless, the presence of major osteoporotic fracture occurring in skeletal sites such as vertebrae, pelvis, humerus and hip demonstrates a bone fragility that requires a more active treatment.

Most anti-fracture treatments are contra-indicated in patients with an eGFR $<30 \mathrm{ml} / \mathrm{min}$. Bisphosphonates accumulate in bone tissues, this being promoted with reduced renal clearance and subsequently might induce defects of bone mineralization and osteomalacia [96]. Albeit there is no evidence of such a deleterious effect, the use of bisphosphonates requires being aware of such possible complication. Few studies and early post hoc analyses showed increased BMD with bisphosphonates, but a systematic review suggested that no evidence that these treatments could be helpful in CKD as no anti-fracture effect has been shown [97]. Denosumab, an anti-RANKL biologic therapy not cleared by the kidney, offered new opportunities for managing fractures. In a subgroup of 73 women with CKD stage 4, denosumab increased the BMD in a similar manner than in women with CKD stages $1-3$, but the low number of patients did not allow to demonstrate an effect in fracture prevention [98]. In patients with CKD stages 4-5D with severe SHPT, denosumab promoted marked hypocalcemia and increased PTH level within the first 15 days of its administration, which often required calcium supplementation. Therefore, a close monitoring is recommended during those first weeks in patients with advanced CKD. A trial compared the oneyear effect of denosumab to alendronate in dialysis patients with low PTH and found that there was a better increase in BMD and improvement of bone biomarkers associated with denosumab [99]. In the absence of linear relation between BMD and fracture risk in CDK, the increase in BMD does not fully secure the effect on the prevention of the risk of fracture at short and long term. Further trials are needed to test the effect of such a medication in both BMD and fracture risk.

Recommendations for the management of fractures in CKD patients rely more on clinical experience than on scientifically well-proven evidence (Fig. 1). First characterization is based on the BMD measurements, followed by the PTH and bone-specific alkaline phosphatase levels. In patients with high PTH, the reduction of SHPT improved other biological parameters and the bone status. Indeed, accounting for differences in baseline characteristics, multiple fractures, and/or events prompting discontinuation, oral cinacalcet efficiently reduced the rates of clinical fractures in elderly dialysis patients [38]. In these patients, denosumab might be discussed once PTH target has been achieved and that BMD remains significantly low [100]. The indication of a subtotal surgical parathyroidectomy should also be discussed in case of persistent and uncontrolled hypercalcemia, hyperphosphatemia, and high serum PTH levels, as well as in cases of progressive vascular calcifications, calciphylaxis, multiple skeletal fractures, and cardiac complications (Fig. 2).

The more challenging situation is the treatment of patients with low PTH. The restoration of PTH levels to the "2-9 time-fold" target is recommended to ensure a proper function of bone cells and a replacement of old to new bone matrix. This could be achieved by reducing calcium load either through the diet or lowering calcium content in the dialysate [101]. More specific anti-resorbing therapy may promote adynamic bone disease and the emergence of vascular calcifications. However, denosumab does not induce any aortic calcifications in postmenopausal women without renal failure [102] and there are no data in humans showing that reducing bone turnover would increase the risk of vascular calcifications. In addition, denosumab reduces the deposition of calcium in vessels of osteopenic mice [103]. Further studies are needed to determine whether this drug has an impact on vascular calcifications in CKD. 


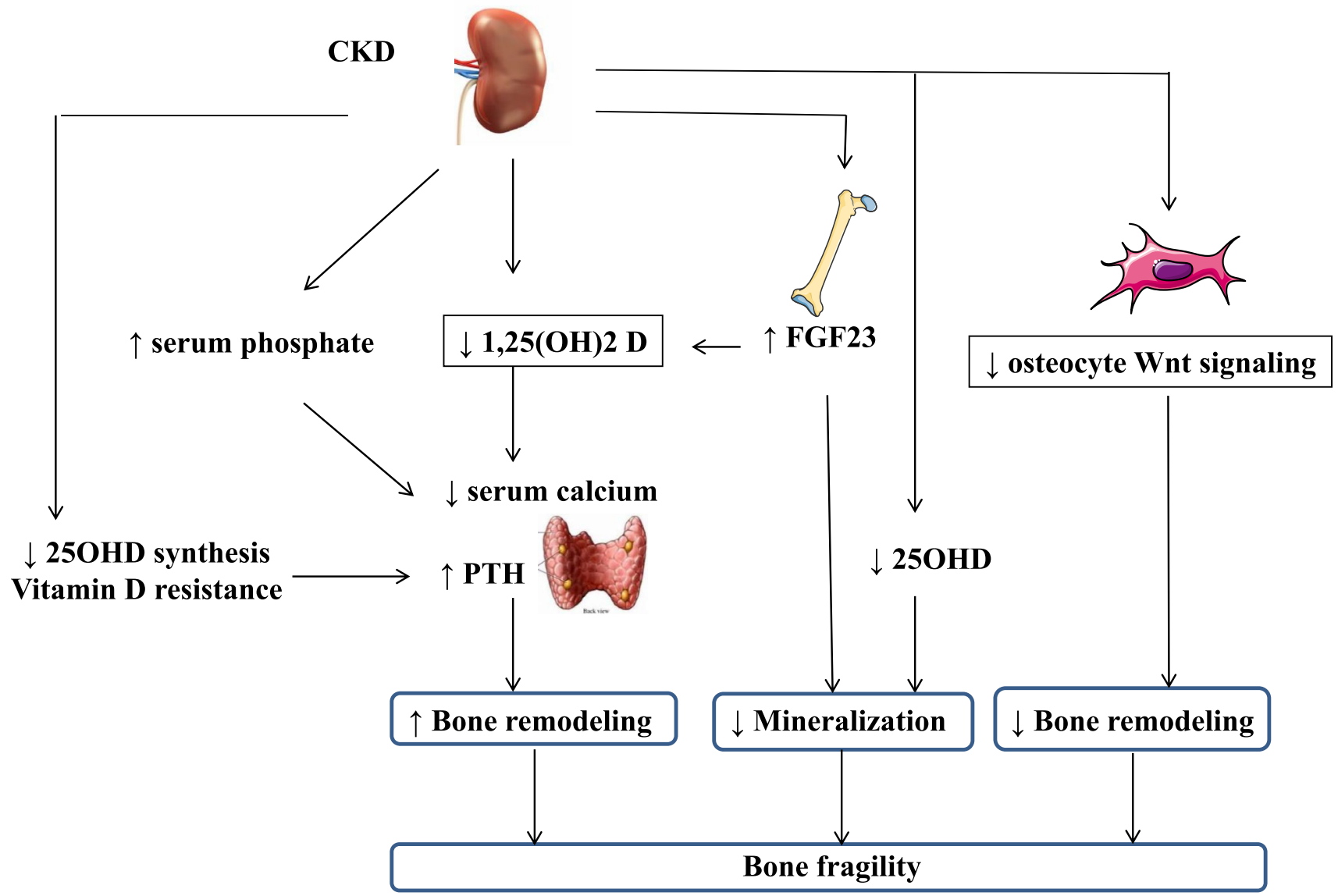

Fig. 1 Pathophysiology of fractures in CKD. Schematic representation of the changes induced by CKD: 25OHD 25hydroxy-vitamin D; 1,25(OH)2 D: 1-25 dihydroxy-vitamin D. PTH parathyroid hormone; Wnt wintless

To the best of knowledge, the optimal therapy for CKDassociated osteoporosis would be a drug that enhances bone formation and restores bone mass. In this sense, the effect of teriparatide has been evaluated in a small pilot study including 7 hemodialysis patients. There was a significant increase in lumbar and femoral BMD after 6 months of treatment and in 6 out of the 7 patients [104]. However, we are lacking evidence regarding the effect of teriparatide on the prevention of fractures in advanced CKD. Anti-sclerostin antibody is a promising anabolic agent as it promotes bone formation by binding to sclerostin, a natural antagonist of Wnt signaling. Indeed, romosozumab increased BMD and prevents bone fractures in postmenopausal women without CKD [105].
Interestingly, anti-sclerostin antibody increases bone formation and bone mass in rats with CDK only with low, but not with high PTH [106]. Trials based on this promising therapy in CKD are highly awaited taking into account the alert on the possible cardiovascular side effects.

In conclusion, the high incidence of fractures and mortality in patients with CKD requires a better evaluation of fracture risk, as well as more randomized controlled trials on fracture prevention. Because of the multiple aspects of bone fragility in CKD, a multidisciplinary discussion including renal and bone experts in CKD-MBD would be desirable before any initiation of specific bone treatments. 


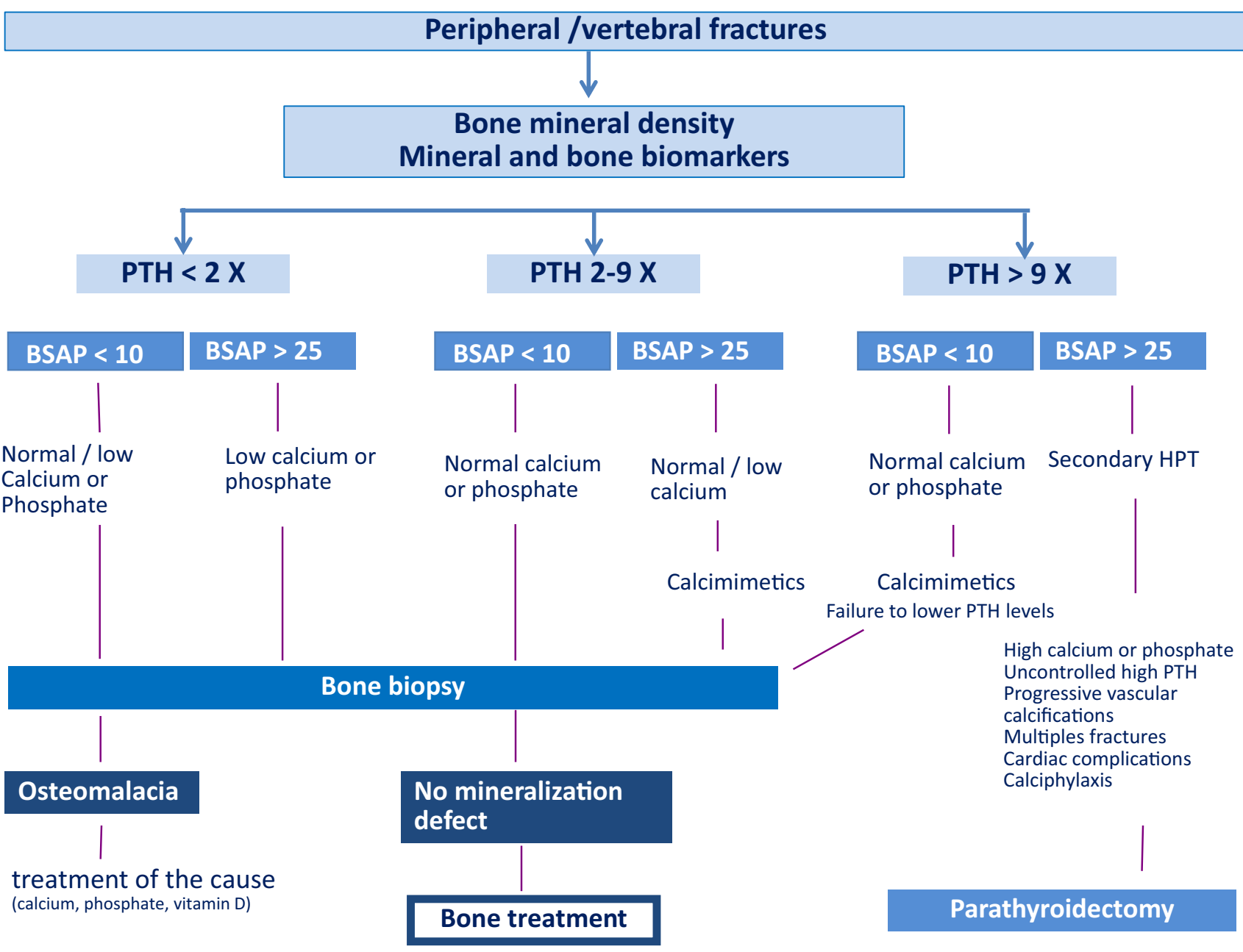

Fig. 2 Guidelines for the management of fractures. A fragility fracture requires the measurement of bone mineral density and a deep analysis of mineral metabolism markers. The first step aims to rule out an osteomalacia with the use of bone biomarkers and if possible a bone biopsy. Guidelines are proposed as a function of PTH levels. Reduction of PTH should be achieved before the introduction of any anti-resorbing agents. BSAP bone-specific alkaline phosphatase
Author Contributions All the authors contributed to the writing, and all approved the final version of the manuscript.

Funding There was no support in relation to the work. the article's Creative Commons licence and your intended use is not permitted by statutory regulation or exceeds the permitted use, you will need to obtain permission directly from the copyright holder. To view a copy of this licence, visit http://creativecommons.org/licenses/by/4.0/.

\section{Compliance with Ethical Standards}

Conflict of Interest Ana Pimentel, Pablo Ureña-Torres, Jordi Bover, Jose Luis Fernandez-Martín, and Martine Cohen-Sola declare that they have no conflicts of interest in relation to the work.

Open Access This article is licensed under a Creative Commons Attribution 4.0 International License, which permits use, sharing, adaptation, distribution and reproduction in any medium or format, as long as you give appropriate credit to the original author(s) and the source, provide a link to the Creative Commons licence, and indicate if changes were made. The images or other third party material in this article are included in the article's Creative Commons licence, unless indicated otherwise in a credit line to the material. If material is not included in

\section{References}

1. Beaubrun AC, Kilpatrick RD, Freburger JK et al (2013) Temporal trends in fracture rates and postdischarge outcomes among hemodialysis patients. J Am Soc Nephrol 24:1461-1469. https ://doi.org/10.1681/ASN.2012090916

2. Hansen D, Olesen JB, Gislason GH et al (2016) Risk of fracture in adults on renal replacement therapy: a Danish national cohort study. Nephrol Dial Transplant 31:1654-1662. https://doi. org/10.1093/ndt/gfw073

3. Maravic M, Ostertag A, Torres PU, Cohen-Solal M (2014) Incidence and risk factors for hip fractures in dialysis patients. 
Osteoporos Int 25:159-165. https://doi.org/10.1007/s0019 8-013-2435-1

4. Tentori F, McCullough K, Kilpatrick RD et al (2014) High rates of death and hospitalization follow bone fracture among hemodialysis patients. Kidney Int 85:166-173. https://doi.org/10.1038/ ki.2013.279

5. Danese MD, Kim J, Doan QV et al (2006) PTH and the risks for hip, vertebral, and pelvic fractures among patients on dialysis. Am J Kidney Dis 47:149-156. https://doi.org/10.1053/j. ajkd.2005.09.024

6. Ketteler M, Block GA, Evenepoel P et al (2017) Executive summary of the 2017 KDIGO chronic kidney disease-mineral and bone disorder (CKD-MBD) guideline update: what's changed and why it matters. Kidney Int 92:26-36. https://doi. org/10.1016/j.kint.2017.04.006

7. Group KDIGOC-MW (2009) KDIGO clinical practice guideline for the diagnosis, evaluation, prevention, and treatment of Chronic Kidney Disease-Mineral and Bone Disorder (CKDMBD). Kidney Int Suppl S1

8. Crandall CJ, Larson J, Wright NC et al (2020) Serial bone density measurement and incident fracture risk discrimination in postmenopausal women. JAMA Intern Med 180:1232-1240. https:// doi.org/10.1001/jamainternmed.2020.2986

9. Alem A, Sherrard D, Gillen D et al (2000) Increased risk of hip fracture among patients with end-stage renal disease. Kidney Int 58:396-399. https://doi.org/10.1046/j.1523-1755.2000.00178.x

10. LaCroix AZ, Lee JS, Wu L et al (2008) Cystatin-C, renal function, and incidence of hip fracture in postmenopausal women. J Am Geriatr Soc 56:1434-1441. https://doi.org/10.111 1/j.1532-5415.2008.01807.x

11. Ambrus C, Almasi C, Berta K et al (2011) Vitamin D insufficiency and bone fractures in patients on maintenance hemodialysis. Int Urol Nephrol 43:475-482. https://doi.org/10.1007/s1125 5-010-9723-X

12. Iimori S, Mori Y, Akita W et al (2012) Diagnostic usefulness of bone mineral density and biochemical markers of bone turnover in predicting fracture in CKD stage 5D patients-a single-center cohort study. Nephrol Dial Transplant 27:345-351. https://doi. org/10.1093/ndt/gfr317

13. Wakasugi M, Kazama JJ, Taniguchi M et al (2013) Increased risk of hip fracture among Japanese hemodialysis patients. J Bone Miner Metab 31:315-321. https://doi.org/10.1007/s0077 4-012-0411-z

14. Arneson TJ, Li S, Liu J et al (2013) Trends in hip fracture rates in US hemodialysis patients, 1993-2010. Am J Kidney Dis 62:747754. https://doi.org/10.1053/j.ajkd.2013.02.368

15. Elliott MJ, James MT, Quinn RR et al (2013) Estimated GFR and fracture risk: a population-based study. Clin J Am Soc Nephrol 8:1367-1376. https://doi.org/10.2215/CJN.09130912

16. Nair SS, Mitani AA, Goldstein BA et al (2013) Temporal trends in the incidence, treatment, and outcomes of hip fracture in older patients initiating dialysis in the United States. Clin J Am Soc Nephrol 8:1336-1342.https://doi.org/10.2215/CJN.10901012

17. Mathew AT, Hazzan A, Jhaveri KD et al (2014) Increasing hip fractures in patients receiving hemodialysis and peritoneal dialysis. Am J Nephrol 40:451-457. https://doi.org/10.1159/00036 9039

18. Delgado C, Shieh S, Grimes B et al (2015) Association of self-reported frailty with falls and fractures among patients new to dialysis. Am J Nephrol 42:134-140. https://doi. org/10.1159/000439000

19. Yamamoto S, Kido R, Onishi Y et al (2015) Use of renin-angiotensin system inhibitors is associated with reduction of fracture risk in hemodialysis patients. PLoS ONE 10:e0122691. https:// doi.org/10.1371/journal.pone.0122691
20. Coco M, Rush H (2000) Increased incidence of hip fractures in dialysis patients with low serum parathyroid hormone. Am J Kidney Dis 36:1115-1121. https://doi.org/10.1053/ajkd.2000.19812

21. Stehman-Breen CO, Sherrard DJ, Alem AM et al (2000) Risk factors for hip fracture among patients with end-stage renal disease. Kidney Int 58:2200-2205

22. Dukas L, Schacht E, Stähelin HB (2005) In elderly men and women treated for osteoporosis a low creatinine clearance of $<65 \mathrm{ml} / \mathrm{min}$ is a risk factor for falls and fractures. Osteoporos Int 16:1683-1690. https://doi.org/10.1007/s00198-005-1903-7

23. Jadoul M, Albert JM, Akiba T et al (2006) Incidence and risk factors for hip or other bone fractures among hemodialysis patients in the dialysis outcomes and practice patterns study. Kidney Int 70:1358-1366. https://doi.org/10.1038/sj.ki.5001754

24. Nickolas TL, McMahon DJ, Shane E (2006) Relationship between moderate to severe kidney disease and hip fracture in the United States. J Am Soc Nephrol 17:3223-3232. https://doi. org/10.1681/ASN.2005111194

25. Ensrud KE, Lui L-Y, Taylor BC et al (2007) Renal function and risk of hip and vertebral fractures in older women. Arch Intern Med 167:133. https://doi.org/10.1001/archinte.167.2.133

26. Fried LF, Biggs ML, Shlipak MG et al (2007) Association of kidney function with incident hip fracture in older adults. J Am Soc Nephrol 18:282-286. https://doi.org/10.1681/ASN.20060 50546

27. Dooley AC, Weiss NS, Kestenbaum B (2008) Increased risk of hip fracture among men with CKD. Am J Kidney Dis 51:38-44. https://doi.org/10.1053/j.ajkd.2007.08.019

28. Naylor KL, Garg AX, Zou G et al (2015) Comparison of fracture risk prediction among individuals with reduced and normal kidney function. Clin J Am Soc Nephrol. https://doi.org/10.2215/ CJN.06040614

29. Naylor KL, McArthur E, Leslie WD et al (2014) The threeyear incidence of fracture in chronic kidney disease. Kidney Int 86:810-818. https://doi.org/10.1038/ki.2013.547

30. Maravic M, Ostertag A, Urena P, Cohen-Solal M (2016) Dementia is a major risk factor for hip fractures in patients with chronic kidney disease. Osteoporos Int 27:1665-1669. https://doi. org/10.1007/s00198-015-3429-y

31. Brauer CA (2009) Incidence and mortality of hip fractures in the United States. JAMA 302:1573. https://doi.org/10.1001/ jama.2009.1462

32. de Bruin IJA, Wyers CE, Souverein PC et al (2020) The risk of new fragility fractures in patients with chronic kidney disease and hip fracture-a population-based cohort study in the UK. Osteoporos Int 31:1487-1497. https://doi.org/10.1007/s0019 8-020-05351-x

33. Kim SH, Yi SW, Yi JJ et al (2020) Chronic kidney disease increases the risk of hip fracture: a prospective cohort study in Korean adults. J Bone Miner Res 35:1313-1321. https://doi. org/10.1002/jbmr.3997

34. Wright NC, Saag KG, Curtis JR et al (2012) Recent trends in hip fracture rates by race/ethnicity among older US adults. J Bone Miner Res. https://doi.org/10.1002/jbmr.1684

35. Ball AM, Gillen DL, Weiss NS, et al (2002) Risk of hip fracture among dialysis and renal transplant recipients. J Am Med Assoc 288:3014-3018

36. Atsumi K, Kushida K, Yamazaki K et al (1999) Risk factors for vertebral fractures in renal osteodystrophy. Am J Kidney Dis 33:287-293. https://doi.org/10.1016/S0272-6386(99)70302-1

37. Ureña P, Bernard-Poenaru O, Ostertag A et al (2003) Bone mineral density, biochemical markers and skeletal fractures in haemodialysis patients. Nephrol Dial Transplant 18:2325-2331

38. Moe SM, Abdalla S, Chertow GM et al (2015) Effects of cinacalcet on fracture events in patients receiving hemodialysis: The 
EVOLVE trial. J Am Soc Nephrol 26:1466-1475. https://doi. org/10.1681/ASN.2014040414

39. Castro-Alonso C, D'Marco L, Pomes J et al (2020) Prevalence of vertebral fractures and their prognostic significance in the survival in patients with chronic kidney disease stages 3-5 not on dialysis. J Clin Med 9:1604. https://doi.org/10.3390/jcm9051604

40. Bass E, French DD, Bradham DD, Rubenstein LZ (2007) Riskadjusted mortality rates of elderly veterans with hip fractures. Ann Epidemiol 17:514-519. https://doi.org/10.1016/j.annep idem.2006.12.004

41. Fransen M, Woodward M, Norton R et al (2002) Excess mortality or institutionalization after hip fracture: Men are at greater risk than women. J Am Geriatr Soc 50:685-690. https://doi.org/10.1 046/j.1532-5415.2002.50163.x

42. Nitsch D, Mylne A, Roderick PJ et al (2009) Chronic kidney disease and hip fracture-related mortality in older people in the UK. Nephrol Dial Transplant 24:1539-1544. https://doi.org/10.1093/ ndt/gfn678

43. Bucur RC, Panjwani DD, Turner L et al (2015) Low bone mineral density and fractures in stages 3-5 CKD: an updated systematic review and meta-analysis. Osteoporos Int 26:449-458. https:// doi.org/10.1007/s00198-014-2813-3

44. West SL, Lok CE, Langsetmo L et al (2015) Bone mineral density predicts fractures in chronic kidney disease. J Bone Miner Res 30:913-919. https://doi.org/10.1002/jbmr.2406

45. Yenchek RH, Ix JH, Shlipak MG et al (2012) Bone mineral density and fracture risk in older individuals with CKD. Clin J Am Soc Nephrol 7:1130-1136. https://doi.org/10.2215/CJN.12871 211

46. Jamal SA, Gilbert J, Gordon C, Bauer DC (2006) Cortical pQCT measures are associated with fractures in dialysis patients. J Bone Min Res 21:543-548. https://doi.org/10.1359/jbmr.060105

47. Jamal SA, West SL, Nickolas TL (2014) The clinical utility of FRAX to discriminate fracture status in men and women with chronic kidney disease. Osteoporos Int 25:71-76. https://doi. org/10.1007/s00198-013-2524-1

48. Przedlacki J, Buczyńska-Chyl J, Koźmiński P et al (2020) FRAX prognostic and intervention thresholds in the management of major bone fractures in hemodialysis patients: A two-year prospective multicenter cohort study. Bone 133. doi:https://doi. org/10.1016/j.bone.2019.115188

49. Aleksova J, Milat F, Kotowicz MA et al (2019) Patients with end-stage kidney disease have markedly abnormal cortical hip parameters by dual-energy X-ray absorptiometry. Nephrol Dial Transplant. https://doi.org/10.1093/ndt/gfz195

50. Bredbenner TL, Mason RL, Havill LM et al (2014) Fracture risk predictions based on statistical shape and density modeling of the proximal femur. J Bone Miner Res 29:2090-2100. https:// doi.org/10.1002/jbmr.2241

51. Gracia-Marco L, García-Fontana B, Ubago-Guisado E et al (2020) Analysis of bone impairment by 3D DXA hip measures in patients with primary hyperparathyroidism: a pilot study. $\mathrm{J}$ Clin Endocrinol Metab 105:175-180. https://doi.org/10.1210/ clinem/dgz060

52. McCloskey EV, Odén A, Harvey NC et al (2016) A meta-analysis of trabecular bone score in fracture risk prediction and its relationship to FRAX. J Bone Miner Res 31:940-948. https://doi. org/10.1002/jbmr.2734

53. Naylor KL, Prior J, Garg AX et al (2016) Trabecular bone score and incident fragility fracture risk in adults with reduced kidney function. Clin J Am Soc Nephrol 11:2032-2040. https://doi. org/10.2215/CJN.00720116

54. Malluche HH, Mawad HW, Monier-Faugere MC (2011) Renal osteodystrophy in the first decade of the new millennium: analysis of 630 bone biopsies in black and white patients. J Bone Miner Res 26:1368-1376. https://doi.org/10.1002/jbmr.309
55. Nickolas TL, Stein EM, Dworakowski E et al (2013) Rapid cortical bone loss in patients with chronic kidney disease. J Bone Min Res 28:1811-1820. https://doi.org/10.1002/jbmr.1916

56. Malluche HH, Davenport DL, Canto T, Monier-Faugere MC (2014) Bone mineral density and serum biochemical predictors of bone loss in patients with CKD on dialysis. Clin J Am Soc Nephrol 9:1254-1262. https://doi.org/10.2215/CJN.09470913

57. Hasegawa K, Hasegawa Y, Nagano A (2004) Estimation of bone mineral density and architectural parameters of the distal radius in hemodialysis patients using peripheral quantitative computed tomography. J Biomech 37:751-756. https://doi.org/10.1016/ S0021-9290(03)00174-X

58. Cejka D, Patsch JM, Weber M et al (2011) Bone microarchitecture in hemodialysis patients assessed by HR-pQCT. Clin J Am Soc Nephrol 6:2264-2271. https://doi.org/10.2215/CJN.09711 010

59. Nickolas TL, Jamal SA (2015) Bone kidney interactions. Rev Endocr Metab Disord 16:157-163. https://doi.org/10.1007/s1115 4-015-9314-3

60. Bacchetta J, Boutroy S, Vilayphiou N et al (2009) Early impairment of trabecular microarchitecture assessed with HR-pQCT in patients with stage II-IV chronic kidney disease. J Bone Miner Res 25:090923081446048-24. https://doi.org/10.1359/ jbmr.090831

61. Pereira RC, Bischoff DS, Yamaguchi D et al (2016) Micro-CT in the assessment of pediatric renal osteodystrophy by bone histomorphometry. Clin J Am Soc Nephrol 11:481-487. https://doi. org/10.2215/CJN.04810515

62. Benillouche E, Ostertag A, Marty C et al (2020) Cortical bone microarchitecture in dialysis patients. Am J Nephrol 51:833-838. https://doi.org/10.1159/000510064

63. Marques IDB, Araújo MJCLN, Graciolli FG et al (2017) Biopsy vs. peripheral computed tomography to assess bone disease in CKD patients on dialysis: differences and similarities. Osteoporos Int 28:1675-1683. doi:https://doi.org/10.1007/s0019 8-017-3956-9

64. Nuzzo S, Lafage-Proust MH, Martin-Badosa E et al (2002) Synchrotron radiation microtomography allows the analysis of threedimensional microarchitecture and degree of mineralization of human iliac crest biopsy specimens: effects of etidronate treatment. J Bone Miner Res 17:1372-1382. https://doi.org/10.1359/ jbmr.2002.17.8.1372

65. Hesse B, Varga P, Langer M et al (2015) Canalicular network morphology is the major determinant of the spatial distribution of mass density in human bone tissue: Evidence by means of synchrotron radiation phase-contrast nano-CT. J Bone Miner Res 30:346-356. https://doi.org/10.1002/jbmr.2324

66. Bielesz B, Patsch JM, Fischer L et al (2017) Cortical porosity not superior to conventional densitometry in identifying hemodialysis patients with fragility fracture. PLoS ONE 12:1-12. https:// doi.org/10.1371/journal.pone.0171873

67. Heaf J (2001) Causes and consequences of adynamic bone disease. Nephron 88:97-106.

68. Behets GJ, Spasovski G, Sterling LR et al (2015) Bone histomorphometry before and after long-term treatment with cinacalcet in dialysis patients with secondary hyperparathyroidism. Kidney Int 87:846-856. https://doi.org/10.1038/ki.2014.349

69. Barreto FC, Barreto DV, Moysés RMA et al (2008) K/DOQIrecommended intact PTH levels do not prevent low-turnover bone disease in hemodialysis patients. Kidney Int 73:771-777. https://doi.org/10.1038/sj.ki.5002769

70. Lertdumrongluk P, Lau WL, Park J et al (2013) Impact of age on survival predictability of bone turnover markers in hemodialysis patients. Nephrol Dial Transplant 28:2535-2545. https://doi. org/10.1093/ndt/gft290 
71. Fuller DS, Pisoni RL, Bieber BA et al (2013) The DOPPS practice monitor for US dialysis care: trends through December 2011. Am J Kidney Dis 61:342-346. https://doi.org/10.1053/j. ajkd.2012.10.002

72. Guh J-Y, Chen H-C, Chuang H-Y et al (2002) Risk factors and risk for mortality of mild hypoparathyroidism in hemodialysis patients. Am J Kidney Dis 39:1245-1254. https://doi. org/10.1053/ajkd.2002.33398

73. Lu K-C, Ma W-Y, Yu J-C et al (2012) Bone turnover markers predict changes in bone mineral density after parathyroidectomy in patients with renal hyperparathyroidism. Clin Endocrinol (Oxf) 76:634-642. https://doi.org/10.1111/j.1365-2265.2011.04265.x

74. Yajima A, Inaba M, Tominaga Y et al (2010) Increased osteocyte death and mineralization inside bone after parathyroidectomy in patients with secondary hyperparathyroidism. J Bone Miner Res 25:2374-2381. https://doi.org/10.1002/jbmr.126

75. Rudser KD, de Boer IH, Dooley A et al (2007) Fracture risk after parathyroidectomy among chronic hemodialysis patients. J Am Soc Nephrol 18:2401-2407. https://doi.org/10.1681/ASN.20070 10022

76. Salam S, Gallagher O, Gossiel F et al (2018) Diagnostic accuracy of biomarkers and imaging for bone turnover in renal osteodystrophy. J Am Soc Nephrol 29:1557-1565. https://doi. org/10.1681/ASN.2017050584

77. Nickolas TL, Chen N, McMahon DJ et al (2020) A microRNA approach to discriminate cortical low bone turnover in renal osteodystrophy. JBMR Plus 4. doi:https://doi.org/10.1002/ jbm4.10353

78. Prié D, Torres PU, Friedlander G (2009) Latest findings in phosphate homeostasis. Kidney Int 75:882-889. https://doi. org/10.1038/ki.2008.643

79. Campos-Obando N, Koek WNH, Hooker ER et al (2017) Serum phosphate is associated with fracture risk: the Rotterdam study and MrOS. J Bone Miner Res 32:1-12. https://doi.org/10.1002/ jbmr.3094

80. Block GA, Klassen PS, Lazarus JM et al (2004) Mineral metabolism, mortality, and morbidity in maintenance hemodialysis. J Am Soc Nephrol 15:2208-2218. https://doi.org/10.1097/01. ASN.0000133041.27682.A215/8/2208[pii]

81. Aleksova J, Wong P, Mulley WR et al (2017) Serum phosphorus levels and fracture following renal transplantation. Clin Endocrinol (Oxf) 87:141-148. https://doi.org/10.1111/cen.13363

82. Dhayat NA, Ackermann D, Pruijm M et al (2016) Fibroblast growth factor 23 and markers of mineral metabolism in individuals with preserved renal function. Kidney Int 90:648-657. https ://doi.org/10.1016/j.kint.2016.04.024

83. Urena Torres P, Friedlander G, de Vernejoul MC et al (2008) Bone mass does not correlate with the serum fibroblast growth factor 23 in hemodialysis patients. Kidney Int 73:102-107. https ://doi.org/10.1038/sj.ki.5002622

84. Ribeiro AL, Mendes F, Carias E et al (2020) FGF23-klotho axis as predictive factors of fractures in type 2 diabetics with early chronic kidney disease. J Diabetes Complications 34https://doi. org/10.1016/j.jdiacomp.2019.107476

85. Bacchetta J, Cochat P, Salusky IB, Wesseling-Perry K (2012) Uric acid and IGF1 as possible determinants of FGF23 metabolism in children with normal renal function. Pediatr Nephrol 27:1131-1138. https://doi.org/10.1007/s00467-012-2110-3

86. Carrillo-López N, Panizo S, Alonso-Montes C et al (2016) Direct inhibition of osteoblastic Wnt pathway by fibroblast growth factor 23 contributes to bone loss in chronic kidney disease. Kidney Int 90:77-89. https://doi.org/10.1016/j.kint.2016.01.024

87. Moe S, Drüeke T, Cunningham J et al (2006) Definition, evaluation, and classification of renal osteodystrophy: a position statement from Kidney Disease: Improving Global Outcomes
(KDIGO). Kidney Int 69:1945-1953. https://doi.org/10.1038/ sj.ki.5000414

88. Levin A, Bakris GL, Molitch M et al (2006) Prevalence of abnormal serum vitamin D, PTH, calcium, and phosphorus in patients with chronic kidney disease: results of the study to evaluate early kidney disease. Kidney Int 71:31-38. https://doi.org/10.1038/ sj.ki.5002009

89. Moranne O, Froissart M, Rossert J et al (2009) Timing of onset of CKD-related metabolic complications. J Am Soc Nephrol 20:164-171. https://doi.org/10.1681/ASN.2008020159

90. Lehmann G, Ott U, Kaemmerer D et al (2008) Bone histomorphometry and biochemical markers of bone turnover in patients with chronic kidney disease stages 3-5. Clin Nephrol 70:296-305

91. Spasovski GB, Bervoets AR, Behets GJ et al (2003) Spectrum of renal bone disease in end-stage renal failure patients not yet on dialysis. Nephrol Dial Transpl 18:1159-1166. doi:https://doi. org/10.1093/ndt/gfg116

92. Tomiyama C, Carvalho AB, Higa A et al (2010) Coronary calcification is associated with lower bone formation rate in CKD patients not yet in dialysis treatment. J Bone Miner Res 25:499504. https://doi.org/10.1359/jbmr.090735

93. Sprague SM, Bellorin-Font E, Jorgetti V et al (2016) Diagnostic accuracy of bone turnover markers and bone histology in patients with CKD treated by dialysis. Am J Kidney Dis 67:559-566. https://doi.org/10.1053/j.ajkd.2015.06.023

94. Drüeke TB, Massy ZA (2016) Changing bone patterns with progression of chronic kidney disease. Kidney Int 89:289-302. https ://doi.org/10.1016/j.kint.2015.12.004

95. Hurtgen C, Morelle J, Vande BB, Jadoul M (2015) The case I bilateral severe mechanical joint pain in the lower limbs in a hemodialysis patient. The diagnosis I hypophosphatemia-induced osteomalacia. Kidney Int 88:207-208. https://doi.org/10.1038/ ki.2014.201

96. Rodd C (2001) Bisphosphonates in dialysis and transplantation patients: efficacy and safety issues. Perit Dial Int 21(Suppl 3):S256-S260

97. Wilson LM, Rebholz CM, Jirru E et al (2017) Benefits and harms of osteoporosis medications in patients with chronic kidney disease. Ann Intern Med 166:649. https://doi.org/10.7326/ M16-2752

98. Jamal SA, Ljunggren Ö, Stehman-Breen C et al (2011) Effects of denosumab on fracture and bone mineral density by level of kidney function. J Bone Miner Res 26:1829-1835. https://doi. org/10.1002/jbmr.403

99. Iseri K, Watanabe M, Yoshikawa $\mathrm{H}$ et al (2019) Effects of denosumab and alendronate on bone health and vascular function in hemodialysis patients: a randomized, controlled trial. J Bone Miner Res 34:1014-1024. https://doi.org/10.1002/jbmr.3676

100. Chen NC, Hsu CY, Chen CL (2017) The strategy to prevent and regress the vascular calcification in dialysis patients. Biomed Res Int 2017.https://doi.org/10.1155/2017/9035193

101. Fiedler R, Deuber HJ, Langer T et al (2004) Effects of reduced dialysate calcium on calcium-phosphorus product and bone metabolism in hemodialysis patients. Nephron - Clin Pract 96:c3-c9. https://doi.org/10.1159/000075565

102. Samelson EJ, Miller PD, Christiansen C et al (2014) RANKL inhibition with denosumab does not influence 3-year progression of aortic calcification or incidence of adverse cardiovascular events in postmenopausal women with osteoporosis and high cardiovascular risk. J Bone Miner Res 29:450-457. https://doi. org/10.1002/jbmr.2043

103. Helas S, Goettsch C, Schoppet M et al (2009) Inhibition of receptor activator of NF- $\mathrm{KB}$ ligand by denosumab attenuates vascular calcium deposition in mice. Am J Pathol 175:473-478. https:// doi.org/10.2353/ajpath.2009.080957 
104. Cejka D, Kodras K, Bader T, Haas M (2010) Treatment of hemodialysis-associated adynamic bone disease with teriparatide (PTH1-34): a pilot study. Kidney Blood Press Res 33:221-226. https://doi.org/10.1159/000316708

105. Cosman F, Crittenden DB, Adachi JD et al (2016) Romosozumab treatment in postmenopausal women with osteoporosis. N Engl J Med 375:1532-1543. https://doi.org/10.1056/NEJMoa1607948
106. Moe SM, Chen NX, Newman CL et al (2015) Anti-sclerostin antibody treatment in a rat model of progressive renal osteodystrophy. J Bone Miner Res 30:499-509. https://doi.org/10.1002/ jbmr.2372

Publisher's Note Springer Nature remains neutral with regard to jurisdictional claims in published maps and institutional affiliations. 